\title{
Eurofound's Reference Framework: Sustainable work over the life course in the EU
}

Franz Ferdinand Eiffe

\section{Abstract}

Demographic change has triggered policy debates and responses across Europe. The need for keeping workers in employment longer is a consequence that requires rethinking: new solutions for working conditions and career paths helping workers to retain their physical and mental health: as well as motivation and productivity, throughout an extended working life. Eurofound has defined sustainable work as the interplay of working and living conditions being such "that they support people in engaging and remaining in work throughout an extended working life" (Eurofound, 2015, p.5). The definition of sustainability in the context of work implies simultaneous efforts towards achieving individual, social and economic work- and labour market-related goals that will enable the needs of the present worker to be met without compromising his/her ability of future work. Identifying and analysing the factors and actions underpinning sustainable work throughout working life has been a research priority for Eurofound since 2013. This article discusses the Eurofound reference framework of sustainable work over the life course and its components. It presents sustainable work outcome indicators on the societal and the individual level and provides some reflections of how those can be used jointly to map overall beneficial work environments for sustainable work. The article investigates contextual factors such as infrastructures, workplace practices and job quality. The specific role of motivation is also highlighted with empirical analysis. The paper closes with conclusions and a policy outlook.

Keywords: Sustainable work, life course perspective, EU context, indicators

About Eurofound

Founded in 1975 and located in Dublin, Ireland, the European Foundation for the Improvement of Living and Working Conditions (Eurofound) is a tripartite European Union Agency, whose role is to provide information, advice and expertise on working conditions and sustainable work, industrial relations, labour market change and quality of life and public services, to support the EU Institutions and bodies, Member States and Social Partners in 
shaping and implementing social and employment policies, as well as promoting social dialogue on the basis of comparative information, research and analysis.

\section{Introduction}

Demographic change has triggered policy debates and responses across Europe. The need for keeping workers in employment longer is a consequence that requires rethinking: new solutions for working conditions and career paths helping workers to retain their physical and mental health: as well as motivation and productivity, throughout an extended working life. Given the pressures of demographic change, a work environment needs to be created that satisfies the needs of different groups of workers: not only older workers but also those with care responsibilities, for example, or people with physical disabilities or mental health problems, to allow for the participation of the largest possible numbers in the labour force.

Eurofound has titled the broad goal set out by this statement as 'making work sustainable over the life course'. Identifying and analysing the factors and actions underpinning sustainable work throughout working life has been a research priority for Eurofound since 2013. In a first step, the rather expansive concept of sustainable work was illuminated by a framework that explains our approach, and that has been used as reference point for a range of Eurofound research projects examining different aspects of sustainable work (e.g., Eurofound, 2015, 2016a, 2017a, 2017b).

In this paper, the Eurofound reference framework of sustainable work is introduced and its components are discussed. Section 2 presents sustainable work outcome indicators on the societal and the individual level, and provides some reflections of how those can be used jointly to map overall beneficial work environments for sustainable work. Section 3 investigates contextual factors such as infrastructures, workplace practices and job quality. The specific role of motivation is highlighted in section 4 based on empirical analysis. The paper closes with some conclusions and a policy outlook.

\section{The Eurofound framework of sustainable work over the life course}

Eurofound first published a conceptual paper on Sustainable Work over the Life Course in 2015. There, sustainable work is defined as the interplay of working and living conditions being such "that they support people in engaging and remaining in work throughout an extended working life" (Eurofound, 2015, p.5). Eurofound hence takes he perspective of the working individual being in a concrete job situation (job quality, work organisation) that interacts with its private life domain. Key features are around job quality, work-life balance, developing skills and employability, having enough earnings etc. The issue of addressing critical life events and being supported through transitions is a further crucial element in our approach. In addition, the framework opens a societal perspective by emphasising the central role of policies, 
infrastructures, regulations and practices in shaping both the individual and work context to unfold within the institutional settings and socio-economic developments

With the objective of bringing this concept a step further, Eurofound commissioned a feasibility study (Virtanen et al., 2018) with the guiding research question of how and to what extent the conceptual framework can be operationalised in order to measure outcomes of sustainable work and associated determinants. Based on extensive literature research and the consultation of leading experts in the field, the authors of this study developed, together with Eurofound, an analytical reference framework mapping out the main constituents of sustainable work and their interrelations as illustrated in Figure 1. Consequently, the single components of the reference framework were operationalised, and key measures selected, composing a final dashboard of indicators.

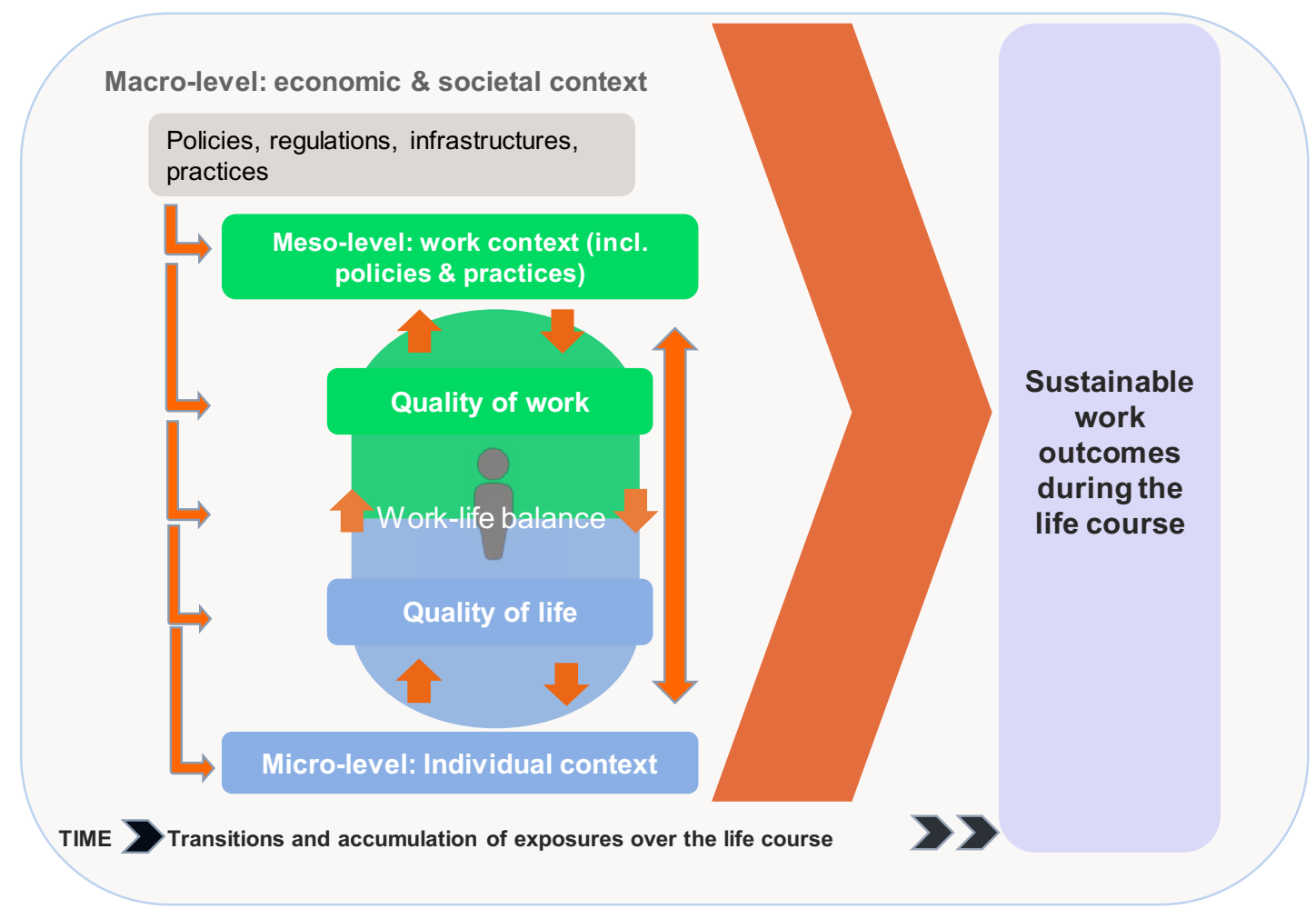

Figure 1 Eurofound Sustainable Work Framework

Source: Virtanen et al, 2017 @ Eurofound

\section{What are sustainable work outcomes?}

Can sustainable work be measured? Yes and no. No, because there is no single indicator which captures the whole nature of the phenomenon as outlined above; and yes, because as the literature demonstrates, there are various indicators that summarise outcomes reflecting a sustainable work environment. However, there are many ways of measuring one or other aspect of sustainable work, and previous research has shown various efforts of how to do it (e.g., Fleuren, 2019). Eurofound's approach adds a new angle to this debate in bringing both 
the macro- and micro-perspective together, arguing that both essentially contribute to understanding the full scope of the phenomenon.

Sustainable work outcome indicators were proposed by Eurofound, in order to operationalise the framework's underlying definition as quoted above ("engaging and remaining in work throughout an extended working life"). They refer to increased labour market participation across the life cycle. The indicators hence quantify objectives related to sustainable work or results of sustainable work environments on various levels (individual, macro). First, they capture the societal and economic objective of keeping workers longer in the labour market due to population ageing, demographic change and financial constraints (e.g., as regards sustainable pension systems and public finance). Secondly, they refer to the individual worker and his/her labour market trajectory (fulfilling work; ability to work until/beyond retirement age; labour market history and transitions).

The definition of sustainability in the context of work implies simultaneous efforts towards achieving individual, social and economic work; and labour market-related goals that will enable the needs of the present worker to be met without compromising his/her ability of future work. This requires for one sustainable conditions at the current job (e.g. regarding effects on workers' health), the worker's ability, willingness and motivation to do this job (or a similar one) now and in the future (health, skills, work engagement) (see e.g. Eurofound, 2018a) and the institutional preconditions for workers to participate in the labour market (available jobs, employment levels, labour market services). While the selection of indicators depends on various factors such as the scope of the study, data availability and data quality, Eurofound suggests a couple of specific indicators on two levels that are comparable across EU Member States.

\section{Macro-level}

The indicators proposed at societal level illuminate various aspects of what the OECD (2006) once called Live longer, Work longer. While the outcome indicators deliver snapshots of the situation of Member States at a certain time, they also feed into policy debates of giving people better choices and incentives to continue working at an older age. They allow for evaluating whether work systems are sustainable from a macro-economic policy angle, and deliver useful evidence for policy makers to design policies encouraging greater labour market participation at an older age, by "fostering employability, job mobility and labour market demand" (ebd.). The following indicators were suggested:

Senior employment rate of workers aged 55plus: This indicator was included in the final list for two reasons: First, the employment rate of older workers (and especially its development over the years) gives evidence of a country's capability/capacity to keep the ageing workforce in the labour market. Besides the general employment level and labour market structure, the indicator also highlights how well the interplay of institutional and economic incentives 
(negative or positive) works in encouraging a later transition from work to retirement. Secondly, senior employment levels also imply labour opportunities for this age group and available jobs. Senior employment levels in themselves, however, would say little about the overall sustainability of work in a broader understanding. Factors that impact on senior employment at the company and/or local levels would also include age management programmes and initiatives, with the focus of a smooth transitioning from work to retirement with benefits for companies as regards knowledge retention. While there is a longer tradition of such practices in some countries like Sweden or the Netherlands (e.g., Wikström et al., 2018), it requires a cultural shift and change in HR management in other, particularly Eastern European, countries (e.g., Joniaková \& Blštáková, 2015).

The duration of working life provides a measure of the average number of years for a given country and year. It complements the employment rate of older workers by exploring how many years today's young people are expected to be active in the labour market throughout their life course (under the currently prevailing age-specific participation rates). This information adds the life course perspective to the mere quantitative level of employment and can be used to monitor developments in relation to early retirement. The average is computed over all adults in a specific country, and is hence strongly influenced by the proportion of the inactive population outside the labour force. Therefore, no conclusions can be derived about the number of years people who are currently employed, work. The indicator instead emphasises the combined effect of the proportion of the active labour force and life expectancy (Eurostat, 2020). Variation of the measure is mainly explained by the general participation rate. The measure relates to the discussion of sustainable work as it accounts for systemic career interruptions (e.g., shorter duration of women due to childcare responsibilities) and differences in pension ages (between men and women / between workers of different countries).

The final indicator proposed at the macro-level is the measure of healthy life years (HLY) at age 65: The life expectancy of the population beyond retirement age indicates the general health of a population. Whether extra years of life gained through increased longevity are spent in good or bad health is a crucial question introducing the concept of quality of life (years enjoyed free from the limitation of illness or disability) and highlighting the wellfunctioning/wellbeing of a society and its institutions. The indicator hence complements the other two by estimating average health prospects when reaching retirement age /leaving the labour market. HLY also monitor health as a productive factor as it not only improves the situation of individuals, but would also relieve public healthcare expenditure and further boost the likelihood that people continue to work later into life (Eurostat, 2020).

Figure 2 jointly explores the development of all three indicators over a time span of 19 years (2000-2019) for the EU27. Overall, the indicators provide evidence that people work longer today, and that higher proportions of men and women aged 55-64 are active labour market participants than back in 2000. The average duration of working life has increased as has the number of healthy life years at age 65 . The main driver of these developments was the 
continuous growth of female labour market participation, with substantially shrinking gender gaps in all employment-related indicators. This increase went on even during the years of the economic and financial crisis and the subsequent recession (2008-2013).

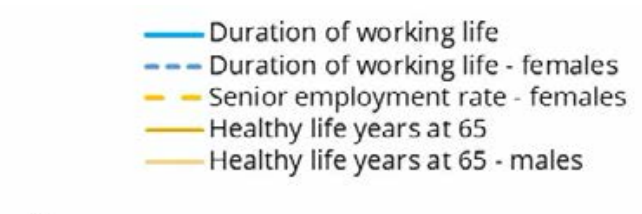

70

60

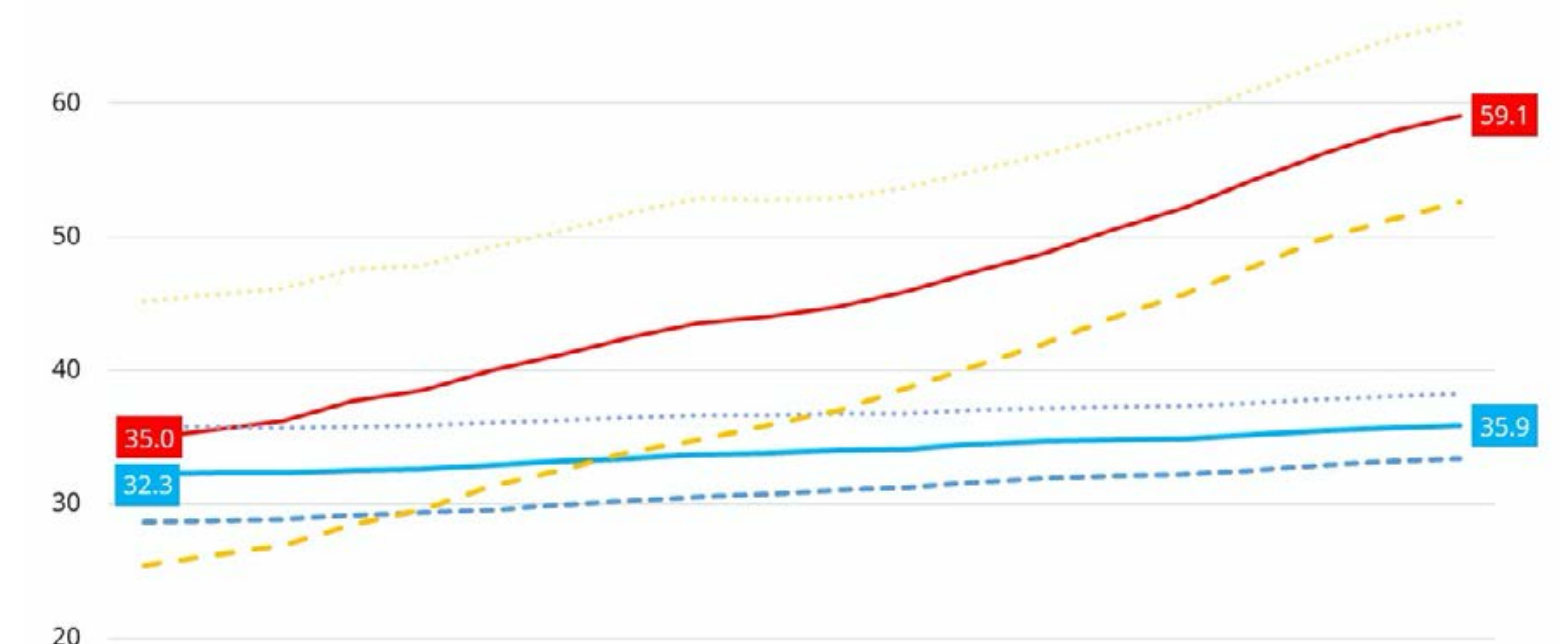

20

10

9.4

0
- Senior employment rate

Duration of working life - males

Healthy life years at 65 - females
- Healthy life years at 65
Senior employment rate - males

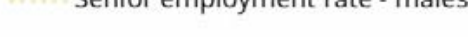

$\begin{array}{llllllllll}2001 & 2003 & 2005 & 2007 & 2009 & 2011 & 2013 & 2015 & 2017 & 2019\end{array}$

\section{Figure 2 Macro-level sustainable work outcomes, EU27}

Source: Eurostat

However, the figure looks at the EU as one single labour market, while both developments and levels differ largely across Member States. Senior employment rates, for instance, range from $79.8 \%$ in Sweden to $48.9 \%$ in Luxembourg. Similarly, the duration of working life is highest in Sweden, Denmark and the Netherlands with over 40 years and lowest in Italy, Croatia and Greece with figures around 33 years. Healthy life years at 65 range from 15.7 in Sweden to 4.4 in Slovakia. This highlights that both health- and labour market-related sustainable work outcomes vary hugely among Member States, and makes a case for countrylevel analysis and monitoring.

\section{Micro-level (individual)}

The outcome indicators at individual level explore work engagement, work ability and health outcomes. They are a crucial complement to the macro-level measures as they introduce 
individual work outcomes. Data availability at the micro level lacks well behind the long time series and well-established data basis of the macro indicators. Some are only available for a single year, and the concepts behind (such as work engagement) are relatively new. Still, we believe that a first step is achieved with these indicators being part of the EWCS programme. Inclusion into the LFS and further conceptual development would be desirable for future monitoring.

Work engagement (tot. / 55+) has been defined as a "positive, fulfilling, work related state of mind that is characterised by vigour, dedication and absorption" (Schaufeli \& Bakker, 2003). The concept describes the relationship of the worker with his or her work and the organisation (Green et al., 2017; Van Dam et al., 2017). Engagement has emerged in the last years as the concept that meets both the interest of workers and employers. It was proposed as sustainable work outcome, as it is positively associated with well-being, high levels of job performance and hence sets the conditions for the worker being able to enjoy and stay at work. Engagement at work is an incentive to keep on working. Social partners and public authorities can set the conditions under which engagement flourishes, such as favourable workplace practices, staff involvement etc.

Self-perceived health status of workers (overall/aged 55plus) is the second micro-level indicator suggested. The proportion of workers reporting very good or good health is based on EUSILC and available since 2008. It has been extensively tested in terms of validity and reliability. Workers ' health is both the precondition but also to a certain extent the outcome of labour market participation. Sustainable work is inextricably linked to health and previous research has shown strong links between population 's health and work ability (Eurofound, 2019b, Söderbacker et al., 2020). Some scholars have however argued for a broader conceptualisation of (occupational) health in terms of overall wellbeing as such measure "integrates, but goes beyond, the traditional OSH goal of protecting workers from occupational hazards, to include preventing illness and promoting worker health" (Schulte et al., 2019).

The attitude towards the sustainability of the current job can be captured via the EWCS, where respondents are specifically asked 'Do you think you will be able to do your current job or a similar one until you are 60 years old?'. For respondents aged 56 or older, the question was changed to: 'Do you think you will be able to do your current job or a similar one in five years' time?'. The fact that the proportion of respondents that were unable to answer the question is similar for older and younger workers, might indicate that the question is no more difficult to answer for younger people than it is for those who are older. Nevertheless, the answers to these questions reflect the perception of employees towards the sustainability of their current job. Analyses of which aspects of the job contribute answering 'Yes' to this question shed light on what workers think is important for them to be able to remain in work. From a data quality perspective, the item is however far from being perfect, and further cognitive testing and other data quality measures would be needed. 


\section{Overall assessment: taking a joint perspective}

Table 1 below gives an overview of all sustainable work outcome indicators proposed by Eurofound, and illustrates the width band in each of them across EU27 Member States. The table illustrates the wide range of outcomes among various countries and highlights that there is room for improvement within the European Union in making work overall more sustainable. It emphasises the point that monitoring should take place at Member State level.

Table 1 Overview of sustainable work outcome indictors (micro- and macro-level).

\begin{tabular}{|c|c|c|c|c|c|c|c|c|}
\hline & $\begin{array}{c}\text { Work } \\
\text { engagement } \\
\text { (all workers) } \\
\text { (Scale 0-100) }\end{array}$ & $\begin{array}{c}\text { Work } \\
\text { engagement } \\
(55+) \\
\text { (Scale } 0-100)\end{array}$ & $\begin{array}{c}\text { Very good } \\
\text { or good self- } \\
\text { perceived } \\
\text { health } \\
\text { status (all } \\
\text { workers) } \\
\% \\
\end{array}$ & $\begin{array}{l}\text { Very good or } \\
\text { good self- } \\
\text { perceived } \\
\text { health } \\
\text { status (55- } \\
64) \quad \%\end{array}$ & $\begin{array}{c}\text { Able to do } \\
\text { your current } \\
\text { job until the } \\
\text { age of } 60 \text { (or } \\
\text { in } 5 \text { years } \\
\text { time if }>56 \text { ), } \\
\%\end{array}$ & $\begin{array}{c}\text { Employmen } \\
\text { t rate } \\
(55-64) \\
\%\end{array}$ & $\begin{array}{c}\text { Duration of } \\
\text { working life } \\
\text { (years) }\end{array}$ & $\begin{array}{c}\mathrm{HLY} \text { at age } \\
\quad 65\end{array}$ \\
\hline $\begin{array}{l}\text { Value corresponding } \\
\text { to } 0=\min \end{array}$ & 68.5 & 63.5 & 59.6 & 26.0 & 47.7 & 40.5 & 31.8 & 4.4 \\
\hline $\begin{array}{l}\text { Value corresponding } \\
\text { to } 1=\max \end{array}$ & 79.9 & 84.3 & 92.9 & 88.6 & 79.0 & 80.7 & 46.3 & 15.7 \\
\hline
\end{tabular}

Source: Eurofound, Eurostat

A monitoring tool could take a joint perspective, categorising the sustainable work environment as per a country 's overall performance in the outcome indicators, both at the micro and macro-level. For both analytical and illustrative purposes, composite indicators on both levels could be developed based on normalised sustainable work outcome indicators. On this basis, a sustainable work scale could be developed mapping countries of different categories: Countries with comparatively (i) high outcomes in both societal and individual level outcomes (ii) low outcomes in both, (iii.) a combination of either high macro-level and low micro-level outcomes or (iv) the other way around. However, such exercise would require indepth debates among policy makers, experts and civil society in selecting a final dashboard of outcome indicators and on weights assigned to them.

\section{The context of sustainable work}

In the Eurofound conceptual framework, sustainable work requires a match between the job and availability for work. At certain points during the life course, difficulties may arise in one or both domains. During these transitions, external support might be needed. Transitions take place not only between jobs, but also between employment and unemployment, periods of learning or caring, or when returning to work after a period of illness. Eurofound emphasises two levers that can be used to increase the chances of achieving a match between work and the individual: the improvement of job quality (to better match a person's availability for work) and improving availability for work (to better match the demands of the labour market). Finally, attention should also be paid to policies and practices that support not only those who are employed, but also those who are currently outside the labour market, 
due to, for example sickness absence or unemployment, taking into account the work-life balance, health, work ability, and skills. It is obvious that, from a labour market perspective, some groups face pronounced disadvantages as for instance those with functional impairments, disabilities or chronic diseases. As previous research has shown (e.g., Eurofound, 2018b, 2019c), their options for sustainable work need hence to be boosted by courageous policy responses. These range from social and labour market policy mixes to social partner agreements, the design of the workplace and company-level action (such as applied return-to-work schemes, flexible work arrangements and generally better recognition).

\section{The core context: Job quality}

The most direct and obvious determinant of the sustainability of work is the characteristics of the job. Eurofound's job quality framework $(2012,2017)$ assesses working conditions along seven key dimensions measured at the workplace level based on data from the EWCS. Job quality is defined as an objective measure of the potential impact of the characteristics of jobs on the well-being of workers:

- Skills and discretion: the opportunities for workers to exercise autonomy, apply their skills, participate in the organisation and develop professionally

- Social environment: the extent to which workers experience both supportive social relationships and adverse social behaviour

- Physical environment: the degree to which workers are exposed to physical and environmental risks at work

- Work intensity: the level of time, workload and emotional demands that put pressure on workers

- Prospects: the degree of job security and opportunities to progress in one's career

- Working time quality: the duration, scheduling and flexibility of working time arrangements

- Earnings: the income from work

How do these seven dimensions affect the sustainability of work over the life course? Although this is basically an empirical question that has to be answered by research (see preliminary analysis in Eurofound, 2019), three features of job quality have to be taken into account particularly in order to understand its relationship to the sustainability of work: firstly, each of the dimensions affect the well-being of workers; secondly, although they are often empirically correlated, the relative importance of the different dimensions can vary across jobs; and finally, high quality in one dimension may compensate for lower quality in another. For instance, higher earnings can help to compensate for certain working time quality or work intensity issues. However, one dimension can never perfectly substitute for another, and it is questionable whether certain elements of a job can really be compensated for. Certain physical demands, for instance, cannot be compensated by earnings, as they can have an 
irreversible negative impact on health. In practice, workers may combine either negative or positive scores on all or several dimensions

\section{Employability and skills}

Individual skills and competencies are crucial to entering the labour market and to remaining at work. Lack of skills can result from initial low-level qualifications, changing requirements, obsolescence of skills over time, or simply structural changes in the demand for labour. Keeping skills updated throughout the life course in a changing labour market is challenging. Continuous development of competencies and acquisition of qualifications depends both on lifelong learning opportunities and a person's life and work circumstances. However, a high level of employability is, besides the supply of jobs, one prerequisite for achieving employment security. Conversely, low levels of employability put individuals in danger of losing attachment to a labour market where job security cannot be guaranteed.

\section{Company practices and workplace social dialogue}

Company-level policies are the crucial place for the proper implementation of practices related to sustainable work. The job climate in this regard is shaped by the way in which government regulation and collective agreements are applied in practice, the workers' voice is heard (or not) and worker participation evolves. Company and workplace practices provide the "meso-context" in keeping people being engaged and healthy at the workplace. Companies implement measures affecting job quality but also as regards achieving a better fit between the needs and abilities of the individual and the requirements of the job, and to improving the overall work environment.

Workplace practices and the approach to workplace social dialogue touch upon the core of the work experience. How do companies organise their day-to-day business, and what is the role of employees in the organisation? Inclusive HRM practices and strong employee involvement in decision-making are associated with beneficial performance outcomes as regards innovation, productivity or workplace wellbeing (Eurofound, 2016; 2017). Work engagement is positively associated with organisational justice and other motivational features linked to an active role for the employee at the workplace (Eiffe, 2018). Highinvolvement workplaces better manage to assign active roles to staff, and increase employee commitment and work engagement with positive impacts on performance and productivity. Many workplace practices such as regular staff meetings, employee involvement in decision making or official employee representatives at the workplace all are positively associated with sustainable work outcomes (Eurofound, 2016a, 2020).

However, an active approach to making work sustainable, can help to achieve overarching social objectives. Practices contributing to such goals include, for instance, age management in companies to prevent the premature exit of workers. Apart from adapting the job and the workplace, a possible revision of the role of older workers can be helpful. As the strength of 
the productive characteristics of the old and the young may differ considerably, there is great potential for diversity management to exploit the complementarities of these characteristics and to widen the scope for mutual learning between generations.

\section{Work-life balance}

The reconciliation of working and private life is an important element in the sustainable work framework, as it marks the intersection between job quality and quality of life. The framework ultimately regards a lack of work-life balance as a barrier to employment. The perspective is broader, in the sense that it also takes into account more than just the work-family balance, explicitly taking a life-course perspective, and acknowledging that work and life demands and resources differ across the life-cycle. Striking a balance between work and other aspects of life is increasingly fundamental for workers, and especially so for those with care responsibilities. A balance between employer-friendly and employee-friendly flexibility is also struck at the workplace level. This does not mean that there is a strict trade-off. Many companies in the EU already promote workplace policies that are conducive to work-life balance, in order to attract and retain workers. Modernised work practices such as teleworking, part-time work and flexible working time must be considered as instruments to improve the work-life balance, so that reconciliation becomes feasible. (Eurofound, 2018b).

\section{Social partners}

Although the institutional arrangements and levels of inter-institutional co-operation differ across countries, in most Member States social partners have a role to play alongside the public authorities. Case studies indicated that the social partners have been instrumental in promoting sustainable work in many Member States (Eurofound, 2016a). Social partners often raise awareness, initiate discussions, provide support, and campaign on a number of questions related to low pay, lifelong learning, health and safety, gender equality, and sustainable work as a whole. They need to be heard in the processes of legislation drafting. In some cases, the social partners may use tripartite negotiations to give advice, or put proposals to the government on several issues related to sustainable work, which may have some concrete outcomes. For example, the National Labour Council and the Labour Foundation in Belgium, as well as the Social and Economic Council in the Netherlands, have played a major role in developing advice, which has often been adopted subsequently in key legislation.

For this to work best, however, the social partners need to have an incentive to co-operate and find a compromise. If this happens, it often leads to a better-supported agreement, which can be defended to the workers and employers more easily. Apart from institutionalised tripartite co-operation, various policy frameworks, information campaigns, committees and network projects (usually government-led) may also boost partnership efforts between relevant social partners and policymakers. 
Overall, a strong role taken by the social partners is significant in successfully pursuing strategies contributing to sustainable work and creating a favourable working environment. In general, their contributions can have a wide impact on comprehensive approaches and relevant sectoral policies. Nevertheless, much depends on the institutional and legal frameworks in which the social partners operate, and the extent of inclusion such frameworks provide.

\section{Legislation, policies, infrastructures}

Legislation and public policies intervene at points outside of the workplace across a life course. Social protection systems assist with critical life events (providing, for instance, income support for transition periods, sickness insurance, child benefits, unemployment benefits and pensions). Quality services, for example a comprehensive care infrastructure, provide support, ideally in a coordinated and integrated way. Through legislation, rights to certain working time and leave options (such as part-time work and parental leave) are guaranteed. A range of policies are aimed at creating inclusive labour markets through labour market activation, tackling labour market segregation, and improving access to employment for the disadvantaged. Legislation establishes rights to non-discrimination, including the adaptation of workplaces to workers with special needs, and to lifelong learning. Social partners are involved in the shaping and implementation of these policies and legislative initiatives.

\section{The role of work motivation for sustainable work}

Motivational factors are a key in the decision-taking towards transiting from work to retirement (Pohrt \& Hasselhorn, 2015). Labour market participation in general, and staying in the labour market until or beyond reaching eligibility for pension, require some degree of individual motivation. Particularly, as regards older workers, their motivation of remaining or re-entering the labour market is key for the overall employment rate of this group. Evidence has shown that motivation shifts from extrinsic factors, such as income or reward to intrinsic sources (such as perceiving the job as meaningful) with increasing age (e.g., Barnes-Farell \& Matthews, 2007). The meaningfulness of the job is hence a core factor to keep people in the labour market at older ages.

Eurofound research (Eiffe, 2019) has highlighted the link between motivation and a couple of sustainable work outcomes on the micro-level. The results show that motivation at work, either intrinsically driven by the content of the job, or by organisational factors such as recognition of work well done, appropriate payment, career prospect or fairness, is important for employees in various regards. Motivated employees have higher levels of work engagement, a lower likelihood of their work negatively affecting health, less days of sick leave, and are generally more likely to perceive their job as sustainable. The results also emphasise that motivational categories are linked to varying extents to sustainable work outcomes in all age groups. 


\section{Conclusions and policy discussion}

Eurofound 's concept of sustainable work acknowledges the need of welfare states to extend working lives, and to adapt to new risks (in terms of social protection) by emphasising the necessity to keep a balance between policy measures at the macro-level, favourable work environments and workplace measures and improved job quality. A further essential element is the life-course perspective, underpinning the need to focus on workers of all age groups. This makes sustainable work a complex policy area for which a holistic approach is desirable.

In turn a focus on extending the statutory retirement or other labour-market related measures is not enough to make work sustainable over the life course. Policy makers need to be aware that the workplace itself, and related practices resulting in the perception of justice, recognition, fair payment, career opportunities and motivating environments, matter to achieve this goal (Bakker \& Demerouti, 2014). Hence, work organisation and technological processes need to be designed, so that high-quality jobs result (e.g., Docherty et al., 2008). The systematic measurement of motivation and wellbeing at the workplace can help to develop alert systems for intervention. Consequently, the sustainability of work also, and particularly needs to, be addressed at the workplace. Companies must be prepared and willing to keep and invest in older employees. Governments can support good workplace practices with workplace innovation funds and other instruments to provide consultancy and training. Other, more global, policy measures can build upon such practices.

Eurofound has provided empirical evidence supporting hypotheses on pathways as outlined in the analytical framework of sustainable work (Figure 1): Obvious relationships were for instance found between favourable socio-economic developments, well-functioning welfarestate institutions and overall positive sustainable work outcomes. Previous research also highlighted correlations between high-involvement workplace measures, such as workplace social dialogue and employee involvement, and sustainable work outcomes. Most importantly: Job quality matters, and must be considered the core determinant of sustainable work outcomes.

For monitoring purposes, indicator dashboards can be useful to keep track of developments across various aspects of sustainable work. It was shown in this paper that various indicators capture different phenomena and distinct aspects of sustainable work on micro-, macro, and potentially also on meso-level. Selections of specific indicators are normative choices, and are furthermore based on statistical criteria such as data availability and data quality. While these aspects do not impose problems in themselves, it is essential to properly justify these choices (for instance via broad policy debates involving civil society) and make them explicit. Synthetic measures of sustainable work to illustrate overall desirable outcomes are useful complements supporting the holistic perspective.

However, more research is clearly needed to explore the effectiveness of sustainable work policy mixes. This regards the implementation in various sectors of the labour market (particularly against the backdrop of the growing service sector), assessments of big 
industries vs. SMEs and the relevance of the concept for various types of workers such as self-employed, platform workers and many others.

\section{Policies addressing sustainable work}

Making work sustainable, according to the Eurofound framework, means from a policy point of view to first have technological and organisational design in place to create high quality jobs. This is the basis for creating a fit between structural characteristics of a job (job quality), and the characteristics of an individual in relation to work (abilities, needs, health, skills, etc.), so that they can interact complementarily at the workplace. From a macro-economic point of view, policy makers need to react to developments with growing numbers of retirees straining public budgets and slowing economic growth. Interventions should take place at all levels: government level (legislation, regulation, public services, infrastructure, public funding), sectoral and company level (collective agreements, social dialogue) and individual level (lifelong learning, new learning, upskilling, employability, etc.). In the following a few areas are highlighted (without being exhaustive), where all actors have a stake:

\section{Following up on the OECD Council recommendation on Ageing and employment}

In 2015, the OECD put forward an age-friendly agenda in three broad policy areas with the main objective to promote employment at an older age. These included (i) improving incentives to work at an older age, (ii.) encouraging employers to retain and hire older workers and (iii) improving employability of older workers by adopting a life-cycle approach. (OECD 2019). This is very much in line with the Eurofound sustainable work agenda, and needs to be implemented as part of a new EU 2030 strategy. All areas are crucial for achieving better sustainable work outcomes, and need to be addressed by policy makers at national and EU level.

\section{Activation policies for young and old (life-course perspective)}

While the share of the economically inactive population has substantially declined over the past 15 years (from $27.7 \%$ in 2000 to $21.7 \%$ in 2019 in the EU27), there is still a lot of potential to further integrate inactive people of all age groups into the labour market. A focus must be put on young people not in education, employment or training (NEETs) with the objective to prevent scarring effects for further career paths. Further enforcement of youth guarantees is needed at Member State levels. Customised active labour market policies are key to re-skill and up-skill people at risk of or in unemployment. Policy makers and social partners need to align forces to keep older workers employable and productive to prevent skill obsolescence. A strong focus should lie on closing the age gap in digital literacy.

\section{Work-life balance policies}

The reconciliation of work and private life or work and personal responsibilities is a crucial element in the sustainable work framework, and is key for starting employment, remaining in or returning to work, work engagement and productivity at work (see Eurofound 2018). Worklife balance needs hence to be put at the core of employment policies at EU and national 
level: This includes family leave entitlements and flexible work arrangements for parents and carers as set out in the Directive for work-life balance (adopted in June 2015).

\section{Gender equality and gender mainstreaming}

Though it was not the focal point of this paper, it is well known from previous research that there are substantial differences in sustainable work outcomes between men and women. Gender mainstreaming, and a focus on gender equality, is hence indispensable in designing sustainable work policies. Occupational inequalities in sustainable work are also to be assessed from a gender perspective. Female-dominated occupations as for instance health and care fare relatively poorly regarding many dimensions of job quality, and are overproportionally exposed to emotionally demanding work (Eurofound, 2020a, 2020b) with serious repercussions on health and well-being.

\section{High involvement workplaces}

Previous research has shown that involving workplaces, and well-functioning workplace social dialogue, are likely to produce more motivated, more engaged and more productive and healthier workers (e.g., Eiffe, 2018, Eurofound, 2016; 2017b, Kornelakis et al., 2018). Such evidence should encourage employers and social partners to implement inclusive measures in companies, and to increase employees' voice and active participation in organisational decisions at the workplace.

\section{Return-to-work schemes}

Return-to-work schemes can help to facilitate the re-entry into the labour market after spells of long-term sick leave, for instance of cancer survivors. Multidisciplinary interventions of physical training, psychological and vocational elements can improve return-to-work. Some authors suggest rehabilitation outpatient services in communities or reintegration teams at large workplaces and/or multinational corporations (de Boer et al., 2015). Important shifts in the policy making process are required to guarantee the provision of equitable and supportive legal frameworks for ill-workers. To this end, employment, health and social security systems must co-operate in order to set up coherent return-to-work pathways (Kiasuwa et al., 2018).

\section{Addressing job quality}

The key message of the Eurofound Sustainable Work Framework is that job quality and working conditions are at the core of keeping people engaged and working longer at a better health. Past EU strategies and initiatives (such as the Lisbon Strategy or Europe 2020) have incorporated the view that the conditions under which work is performed need to be looked at. The OECD has agreed in its job strategy that the quality of working environment will be closely monitored. The Joint Assessment Framework (JAF) of the European Commission tracks job quality as a non-recommendation semester objective, and Eurostat provides information on quality of employment on its website. The European Pillar of Social Rights stresses the importance of fair working conditions. However, this proclamation needs to be further filled 
with substance at all levels. A coherent system of regularly monitoring working conditions with key indicators in each dimension could be the backbone of a future Europe 2030 strategy on Employment and Job Quality.

\section{References}

Bakker, A.B. and Demerouti, E. (2014). Job demands-resources theory. Wellbeing: A complete reference guide, pp.1-28.

Barnes-Farrell, J. \& Matthews, R.A. (2007). Age and work attitudes. In Aging and work in the 21st century, 163-186. Psychology Press

de Boer, A.G., Taskila, T.K., Tamminga, S.J., Feuerstein, M., Frings-Dresen, M.H. \& Verbeek, J.H. (2015). Interventions to enhance return-to-work for cancer patients. Cochrane database of systematic reviews, 9.

Docherty, P., Kira, M. and Shani, A.R. (2008). Creating sustainable work systems: Developing social sustainability. Routledge.

Eiffe, F. (2018). Sustainable work - The role of motivation for sustainable work. Eurofound Working Paper Series WPEF18010, Dublin: https://www.eurofound.europa.eu/sites/default/files/wpef18010.pdf

Eiffe, F. (2019). Working conditions and sustainable work - Context of sustainable work: Analysing status quo and progress, Eurofound Working Paper Series WPEF19010, https://www.eurofound.europa.eu/sites/default/files/wpef19010.pdf

Eurofound (2015). Sustainable work over the life course: Concept paper, Publications Office of the European Union, Luxembourg.

Eurofound (2016a). Sustainable work throughout the life course: National policies and strategies, Publications Office of the European Union, Luxembourg.

Eurofound (2016b). Win-win arrangements: Innovative measures through social dialogue at company level, Publications Office of the European Union, Luxembourg.

Eurofound (2017a). Sixth European Working Conditions Survey - Overview report (2017 update), Publications Office of the European Union, Luxembourg.

Eurofound (2017b), Working time patterns for sustainable work, Publications Office of the European Union, Luxembourg

Eurofound (2017c). Innovative changes in European companies: Evidence from the European Company Survey, Publications Office of the European Union, Luxembourg.

Eurofound (2017d). Working conditions of workers of different ages: European Working Conditions Survey 2015 Publications Office of the European Union, Luxembourg.

Eurofound (2018a). Striking a balance: Reconciling work and life in the EU, Publications Office of the European Union, Luxembourg.

Eurofound (2018b). The social and employment situation of people with disabilities, Publications Office of the European Union, Luxembourg.

Eurofound (2019a). Working conditions and workers' health, Publications Office of the European Union, Luxembourg.

Eurofound (2019b). Working conditions and workers' health, Publications Office of the European Union, Luxembourg.

Eurofound (2019c). How to respond to chronic health problems in the workplace? Publications Office of the European Union, Luxembourg. 
Eurofound (2020a). Gender equality at work, European Working Conditions Survey 2015 series, Publications Office of the European Union, Luxembourg.Eurostat, 2020.

Eurofound 2020b. At your service: Working conditions of interactive service workers, European Working Conditions Survey 2015 series, Publications Office of the European Union, Luxembourg.

Fleuren, B.P. (2019). Caught somewhere in time: Conceptualizing, measuring, and predicting sustainable employability (Doctoral dissertation, Maastricht University).

Green, A. and Livanos, I. (2017). Involuntary non-standard employment in Europe. European Urban and Regional Studies, 24(2), 175-192.

Joniaková, Z. and Blštáková, J. (2015). Age management as contemporary challenge to human resources management in Slovak companies. Procedia Economics and Finance, 34, 202-209.

Kiasuwa Mbengia, R., Tiraboschi, M., Bouland, C. \& de Brouwer, C. (2018). How do social security schemes and labor market policies support the return-to-work of cancer survivors? A review article on challenges and opportunities in the European Union.

Kornelakis, A., Veliziotis, M. and Voskeritsian, H. (2018). Improving productivity: the case for employee voice and inclusive workplace practices. ETUI Research Paper-Policy Brief, 1.

OECD (2006). Live Longer, Work Longer. Ageing and Employment Policies. OECD, Paris, France.

OECD (2015). OECD skills outlook 2015: youth, skills and employability. OECD, Paris, France.

OECD (2019). Working Better with Age. Ageing and employment policies, OECD Publsihing, Paris, France. https://doi.org/10.1787/c4d4f66a-en.

Schulte, P.A., Delclos, G., Felknor, S.A. and Chosewood, L.C., (2019). Toward an expanded focus for occupational safety and health: a commentary. International journal of environmental research and public health, 16(24), 4946.

Söderbacka, T., Nyholm, L. and Fagerström, L. (2020). Workplace interventions that support older employees' health and work ability-a scoping review. BMC Health Services Research, 20, 1-9.

van Dam, K., van Vuuren, T. and Kemps, S. (2017). Sustainable employment: the importance of intrinsically valuable work and an age-supportive climate, International Journal of Human Resource Management. doi: 10.1080/09585192.2015.1137607.

Virtanen, M, Ervasti, J, Ropponen, A. (2018). Working conditions - Measuring sustainable work over the life course - feasibility study, Eurofound Working Paper Series WPEF18063, Dublin: https://www.eurofound.europa.eu/sites/default/files/wpef18063.pdf

Wikström, E., Eriksson, E., Karamehmedovic, L. and Liff, R. (2018). Knowledge retention and age managementsenior employees' experiences in a Swedish multinational company. Journal of Knowledge Management, 8.

\section{About the author}

Franz Ferdinand Eiffe is a research officer in the Working Life unit at Eurofound. He is involved in projects on sustainable work, contractual forms of work and upward convergence in the EU. Before joining Eurofound in 2016, he was Head of Unit 'Analysis' at Statistics Austria in Vienna and project leader of 'How is Austria? Measuring wealth and progress beyond GDP'. He holds a PhD in Economics from Vienna University of Economics (WU), where he also worked as research associate from 2005 to 2009 and as a lecturer until 2016. 